\title{
Gravity model analysis of client-facing choice (in terms of probability evaluation of clients' visits to banks)
}

\author{
Mykola Vashchenko
}

Ph.D., General Director of WBM Polska, the Repulic of Poland

Ihor Cherniavskyi

Ph.D., Head of the Sumy branch, PJSC CB "PrivatBank", Ukraine

\begin{abstract}
The crisis of the banking sector caused a massive outflow of bank customers. Due to unfavorable situation in the currency and credit markets - exchange rate, undermining the stability of the course of the national currency, outflow of deposit funds, mass closing of accounts in banks - financial institutions went bust. Public confidence in the banking sector has decreased, and as a result - the banks have begun to lose customers in large numbers. In order to keep up, to survive in conditions of uncertainty, risk, and increased competition, most banks choose development strategies which are aimed at improving customer service, since customer choice and confidence in the bank are the key of successful banking business. That is why all aspects of the bank's activities should be aimed at creating a client base of the bank, sufficient to ensure profit as a result of its activities, to maintain the stability of the client base in the development of the bank. In this regard, the development and implementation of a strategic direction for managing the customer base of the bank deserves more attention than not disposable customer selection. The client base and client selection should be considered as ordinary management objects that require planning and forecasting using pro-technology and modern mathematical tools. Before the management of the bank there is a problem: how to stay in the market and not give up their positions to competitors and attract new clients' attention to the bank. A solution to this problem can be found by using gravity models.
\end{abstract}

Keywords: gravity model, distribution channels of banking services, distribution policy, regional distribution network, efficiency, quality of service.

\section{JEL Classification: F1.}

DOI: 10.21272/bel.1(2).68-77.2017.

(C) The Authors, 2017. This article is published with open access at ARMG Publishing.

\section{Introduction}

The network of PJSC CB "PrivatBank" throughout Ukraine has 2817 branches and outlets, which are approximately 500 less than last year. In particular, there are 79 branches and outlets of the bank in Sumy region, and in the city of Sumy - 33. Thus, there is a general tendency to reduce the number of narrowing of the branch network of PJSC CB "PrivatBank".

This situation shows not only the impact of the general economic crisis on the banking system of the country as a whole, but also the significant impact of the competitive banks that appear annually in the national market.

Therefore, before the bank's management there is a problem: how to stay in the market and not to give up their positions to competitors and attract new clients' attention to the bank. A solution to this problem can be found in using gravity models.

Formation of the value of banking services is based on the key factors of success (competitive advantages) of the bank. And the proximate interaction of the client with the bank is due to the creation of the last favorable conditions of service (a set of technological, industrial and other factors).

Managers of banking institutions need to develop quantitative parameters (metrics) that help to measure and influence the service process with considering that the quality of service perceived by the client and client's future choice are always important. 
If the representation of the provided services corresponds or exceeds the expectations of customers, they can again reach the bank, and if not - customers can lose interest in the banking institution.

Trust in a bank is a key moment in the perception of its client and the main factor when setting up a certain banking institution to establish long-term partnerships.

The subjectivity of consumer perception affects the image of a bank-specific product or bank in general, which is formed by the influence of this process on the client.

The client evaluates the ability of one or another product to satisfy his requests not on the basis of an objective product, but on the basis of the subjective product, that product (image - values) that formed in his mind.

Accordingly, quality is an aggregation of characteristics of an object that relates to its ability to meet established and predictable needs.

Recently, national banks (including with foreign capital) compete mainly not with the product package, but on the quality of their provision.

Accordingly, the quality of service by the bank is a set of mechanisms, steps, rules and attributes that affect customer satisfaction by a contact with the Bank, but are not directly related to the implementation of the main banking business processes (implementation of services). So, to a certain extent, it can be assumed that the main business processes start after the customer satisfies the quality of service and he decides to buy the necessary banking product.

The gravity models can solve the problem of providing high-quality banking services within a specific region or city, by opening new branches of the bank and satisfying the needs of customers.

\section{Methods}

The probability that a client will visit a branch / department of the bank is proposed to be recaptured as follows (1):

$$
P_{i j}=\frac{\prod_{k=1}^{q} a_{k_{i j}}^{\alpha_{k}} / d_{i j}^{\lambda}}{\sum_{i=1}^{n} \prod_{k=1}^{q} a_{k_{i j}}^{\alpha_{k}} / d_{i j}^{\lambda}},
$$

where: $P_{i j}$ - the probability, that $i$-client visits $j$ - branch/department of the bank;

$a_{k_{i j}}$ - the estimation of the $k$ - index, which describes the work of $j$ - branch / department of the bank, obtained as a result of the interview of the $i$ - client;

$\alpha_{k}$ - criterion of elasticity $k$-indicator of a branch /department of the bank;

$q$ - the total number of indicators of the branch / branch of the bank, which are being considered;

$d_{i j}^{\lambda}$ - the distance that the customer has to overcome to get to the $j$ branch / deprtment of the bank;

$\lambda$ - the parameter for assessing the sensitivity of the distance from the $i$ - client to the $j$ - branch / department of the bank, requires a statistical estimate, usually equal to 1 to 3 (in this case, will be equal to 1 );

$n$ - the total number of branches / departments of the bank were taken into the consideration.

In order to find the elasticity criterion, the previous expression must be written in linear form and at the same time introduce a replacement of some of its elements and logarithm the left and the right part of it. So, first we find the logarithm of both parts of the expression (1), after that it will take the form (2): 
$\log \left(P_{i j}\right)=\sum_{k=1}^{q} \alpha_{k} \log \left(a_{k_{i j}}\right)-\lambda \log \left(d_{i j}\right)-\log \left[\sum_{i=1}^{n} \prod_{k=1}^{q} a_{k_{i j}}^{\alpha_{k}} / d_{i j}^{\lambda}\right]$.

We extend formula 2 by $j$, where $j=1,2, \ldots, n$ and divide both its parts into $n$, thus we obtain formula 3 :

$\frac{1}{n} \sum_{j=1}^{n} \log \left(P_{i j}\right)=\sum_{k=1}^{q} \alpha_{k}\left(\frac{1}{n} \sum_{j=1}^{n} \log \left(a_{k_{i j}}\right)\right)-\lambda \frac{1}{n} \sum_{j=1}^{n} \log \left(d_{i j}\right)-\log \left[\sum_{i=1}^{n} \prod_{k=1}^{q} a_{k_{i j}}^{\alpha_{k}} / d_{i j}^{\lambda}\right]$

Introduce averaged values $\tilde{p}_{i}, \tilde{a}_{k i}$ and $\tilde{d}_{i j}$, which are calculated as:

$$
\tilde{p}_{i}=\sqrt[n]{\prod_{j=1}^{n} p_{i j}}, \tilde{a}_{k i}=\sqrt[n]{\prod_{j=1}^{n} a_{k_{i j}}}, \tilde{d}_{i j}=\sqrt[n]{\prod_{j=1}^{n} d_{k_{i j}}},
$$

where $p_{i j}$ - the frequency of visits to the $i$-th client by the $j$ - a branch / department of the bank during the quarter;

$\tilde{p}_{i}$ - the average geometric frequency of visits to the $i$ - client of all branches / deprtments of the bank, which were taken into consideration in the model;

$\tilde{a}_{k i}$ - the average geometric values of the kth index of the bank among all those were taken into consideration, branches / departments of the bank;

$\tilde{d}_{i j}$ - the average distance that the customer has crossed to reach all branches / departmnts of the bank which were taken into consideration in the model during the quarter.

Let's rewrite equation 3 according to the transformations carried out and get the following one:

$$
\log \left(\sum_{i=1}^{n} \prod_{k=1}^{q} a_{k_{i j}}^{\alpha_{k}}\right)=\sum_{k=1}^{q} \alpha_{k} \log \left(\tilde{a}_{k i}\right)-\lambda \log \left(\tilde{d}_{i j}\right)-\log \tilde{p}_{i},
$$

As a result of all transformations, we obtain the following linear regression equation, from which we can now find the coefficients of elasticity acting as the parameters of equation 6 :

$$
\log \left(\frac{p_{i j}}{\tilde{p}_{i}}\right)=\sum_{k=1}^{q} \alpha_{k} \log \left(\frac{a_{i j}}{\tilde{a}_{k i}}\right)-\lambda \log \left(\frac{d_{i j}}{\tilde{d}_{i j}}\right)
$$

Relation on the left side of the regression equation $\frac{p_{i j}}{\tilde{p}_{i}}$ is considered the dependent variable, and $\frac{a_{i j}}{\tilde{a}_{k i}}-$ vector of independent variables of the equation.

\section{Data mining for modeling}

Before begining of accumulation the necessary inputs for the model, it's needful to determine the area which will be investigated. To do this, it's necessary to divide the territories of the city into so-called "attractive" zones, where one branch / department of the investigated bank would be located at least. Researchers of such a problem recommend to consider the territory near the branch /department of the bank within a radius of 2 kilometers. Having determined with the research area, let's move on to estimate the number of inhabitants living in it; quantity, size and type of posting of enterprises, institutions, organizations; the number of people who come every day to work from other districts. For convenience, it is possible to place on the map of the given district points where potential clients of the branch office /department of a bank can focus, and to indicate their numbers. 
The next step is one of the most responsible, since it will be about accumulation input data. To this end, the relevant bank employees should formulate a questionnaire which would include a set of factors that best describes the attractiveness of the branch / branch of the bank for the client. These include: work schedule; work at night; customer service speed; quality of work of the staff; a set of banking services provided by a specific branch / department of the bank; quality of the pedestrian zone near the branch / department of the bank; quality of parking space on the territory of the branch office / department of the bank; possibility to get to a branch / department of the bank with the help of public transport; level of safety of the location of the branch / department of the bank; the facade of the building where the branch / department is located; your option.

The bank's management or the client should independently select from the proposed list at least 7 (the optimal number of parameters for constructing the given model) positions and place for each score according to the 10-point scale. The closer the score is to 10 points, the better the bank ensures its obligations to customers and contrariwise. In addition, the questionnaire must have a field where the respondent could indicate from which part of the district he goes to the branch / department of the Bank to calculate the distance that he overcomes. The value is determined by the bank independently if the respondent is his client. Otherwise, the frequency of visits in the last quarter can be as one of the items in the questionnaire. Note that the customer in the model is not a separate person, but a group of people who are united by the territorial principle. Therefore, the average estimate of a particular parameter of the model is taken into consideration, calculated as an arithmetic mean of the estimates of individual interviewed people. The formation of questionnaires and the collection of information on banks-competitors are conducted by anology.

People can be interviewed personally when they visit a branch / department of the bank, by e-mail or social networks as one of the most popular ways of communication today. The findings need to be normalized, as well as check for heteroscedasticity, the presence of which can significantly affect the accuracy of more advanced calculations. Verified prepared data will be substituted into the regression equation 6 and by means of PZ STATISTICA software, we will find regression parameters which will be the coefficients of elasticity for the indicators. We obtain the probability of choosing $i$-client of his $j$-branch /department of the bank, substituting the obtained elasticity coefficients and other collected estimates of model parameters. The probabilities found can be further used to increase the efficiency of the branch / department of the Bank, influencing the individual parameters of the model. The impact of the competitive framework is reflected in the symbol of the expression and, as it becomes clear, has a negative impact on the probability of visiting the branch / department o the bank. Also, on the basis of the results, it is possible to assess in more detail the market share occupied by the branch / department of the investigated bank in the district of the city. Figure 1 (see in Appendix) provides a schematic view of the sequence of actions to assess the likelihood of a client visit to the bank.

Thus, we can draw a number of conclusions regarding to the model:

1. ISI model was taken as the basis of the model;

2. a separate factor was introduced in the numerator and the denominator of the model, that characterizes the distance from the client to the branch / department of the bank as a determinant indicator when a client choose a place of service. The consideration was taken as the distance, not the time that the client spends on the way to the bank, because it would have to separately take into account how the client reached the branch office / department of the bank (by foot, by personal or public transport, etc.);

3. unique indicators of attractiveness of the branch / department of the bank were selected;

4. $\tilde{p}_{i}, \tilde{a}_{k i}$ and $\tilde{d}_{i j}$ calculated as average geometric, since the model is multiplicative;

5. introduction of the justification in choosing the value of the radius of the investigated territory relative to the chosen branch / department of the bank and the number of indicators that describe the attractiveness of the branch / department of the bank;

6. a 10-point scale for assessing the attractiveness of the branch / department of the Bank and the process of the collected information, which prevents the emergence of heteroscedasticity of the results of the model and thereby improves their accuracy.

\section{Results}

Practical calculations concerning the simulation of the probability of a visit to the client's office of the bank were conducted on the example of one of the largest banks in Ukraine - PJSC CB "PrivatBank". Its network 
throughout Ukraine has 2817 branches anddepartments, in Sumy region there are 79 branches and departments of the bank, and in Sumy there are 33 departments, 1 branch, more than 140 ATMs and terminals, as well as 1 VIP-center.

The main number of PrivatBank offices is concentrated in the central part of Sumy, due to the main flow of people that daily circuses through it. Given the total part of Sumy, which is $145 \mathrm{~km}^{2}$, the total number of branches represented by PJSC CB "PrivatBank" and the uneven size of their location, the study broadened the radius of research near some bank branches to $2.5-3 \mathrm{~km}$. According to such principle, in Sumy, we devided into 10-zone zone in accordance with the affiliation of this or that district to the branches of PJSC CB "PrivatBank". At each branch of PJSC KB "PrivatBank" there is a different "load" from the point of view of the number of population living in the vicinity of the branch. The irregularity is the reason for such unevenness of the territorial location of Bank branches. In order to further research, it is precisely the area where, branches are represented of other banks in addition to the branches of PJSC CB "PrivatBank", that act as competitors in relation to it. It is also worth bearing in mind that privatization of the PJSC CB "PrivatBank" network is also considered in this case as competitors. There are 14 branches of banks, including 3 branches of PJSC KB "PrivatBank" in our chosen area of research as well as 10 customer groups. When choosing the last we tried to cover the entire territory of the reaserch area.

In Figure 2 the branches of banks are in Latin letters: Imeksbank (I), PAO Stolichny (S) PJSC National Credit (NC), the branch of PJSC KB PrivatBank (Pv1, Pv2, Pv3) PJSC KB "Khreschatyk" (H) PJSC "DB Sberbank of Russia" (Sb) PJSC "Ukrainian Professional Bank" (UP) PJSC CB "UniCreditBank (UC) PJSC Alfa-Bank" (A), PJSC CB "Nadra" (N) of JSC Oschadbank (O) of PJSC "Russian Standard Bank" (RS). Figures 1-10 indicate the groups of potential clients of banks whose questionnaires were carried out (for example, 1 - residents of student hostels and nearby houses, 2 - adjacent objects to school, etc.).

For the input data needed to construct the model, a field research was conducted, which consists in surveying people belonging to the target groups of clients. In the questionnaire developed by us, the participants of the study could set their grades from 1 to 10 points for each of the criteria of attractiveness for all branches of the bank. The survey was conducted through social networks, as well as a group of bank experts through personal communication with people. The sample for the survey was formed in such way as to take into account the opinion of various age and social groups in the area. It can be considered representative. The processed results of the questionnaires are shown in Table 1 (see in Appendix). After that, we normalized the input data, conducted interim calculations for normalized input data using formulas (4)-(6) to find elasticity coefficients. After all the necessary transformations, you can switch to the search for elasticity coefficients. In this case, they are parameters of the linear regression equation (6). In order to find them, we use PZ STATISTICA software, in particular, the Integrated Multiple Regression module.

The obtained results are shown in Table 2.

Table 2. Regression analysis of integrity estimation of visiting clients of branch /department of the bank according to the gravity model

\begin{tabular}{|l|c|}
\hline \multicolumn{1}{|c|}{ Title of attractiveness } & Values of regression parameters \\
\hline Work schedule & 3.15652 \\
\hline Speed of customer service & 0.67079 \\
\hline Quality of staff & 3.43213 \\
\hline Quality of pedestrian zone near the bank & 2.30993 \\
\hline Quality of parking space on the bank's premises & 3.90857 \\
\hline Possibility to get to the bank branch by public transport & 1.14986 \\
\hline Facade of the bank's department building & 0.26376 \\
\hline
\end{tabular}

As we see, the greatest influence on the overall attractiveness of the department is the quality of the vehicle's parking space on the territory of the bank branch, the quality of work of the staff and the schedule of work of the branch. The coefficient of multiple correlation (R) is equal to 0.92 , the determination coefficient (R2) is 0.84 . The actual value of Fisher's criterion is 4.5431 , which at given degrees of freedom $(7 ; 6)$ overestimate its table value - 4.21. The actual value of student's criterion is 5,635, which at a level of significance of 0.05 and a given degree of freedom (6) exceeds its table value of 1.9431. Testing the model for the presence of hetero-rosedaticity was carried out using the Goldfeld-Kwonndt test. The runaway criterion of Fisher is equal 
to 2.41954 , and its tabular value for the degree of freedom $(2 ; 2)$ is 19.0 . Based on the obtained results of the coefficients of multiple correlation, de-termination, Fisher and Student criteria, and also the Goldfeld-Kfondt test, one can conclude that the constructed model is adequate and the obtained regressions are reliable. This gives the right to use them as criteria of elasticity in the model (1).

The probability of visiting bank's branches by a group of clients obtained on the basis of formula 1 is presented in Table 3.

Table 3. Probability of visiting branches of banks located in the study area in Sumy

\begin{tabular}{|c|c|c|c|c|c|}
\hline \multicolumn{3}{|c|}{ Competitive environment \#1 } & \multicolumn{3}{c|}{ Competitive environment \#2 } \\
\hline $\begin{array}{c}\text { Symbol of the } \\
\text { j-th bank } \\
\text { branch }\end{array}$ & $\begin{array}{c}\text { Full title of the } \\
\text { bank }\end{array}$ & Posibility $P_{i j}$ & $\begin{array}{c}\text { Symbol of the } j- \\
\text { bank branch }\end{array}$ & Full title of the bank & Posibility $P_{i j}$ \\
\hline $\mathrm{I}$ & PJSC "Imexbank" & 0.127 & $\mathrm{~S}$ & PJSC AB "Stolichny" & 0.275 \\
\hline $\mathrm{S}$ & $\begin{array}{c}\text { PJSC AB } \\
\text { "Stolichny" }\end{array}$ & 0.308 & $\mathrm{NC}$ & "National Credit" & 0.227 \\
\hline $\mathrm{Pv} 2$ & $\begin{array}{c}\text { PJSC CB } \\
\text { "PrivatBank" }\end{array}$ & 0.048 & $\mathrm{H}$ & "Khreshchatyk" & 0.018 \\
\hline $\mathrm{O}$ & JSC "Oschadbank" & 0.009 & $\mathrm{UC}$ & "UniCreditBank" & 0.027 \\
\hline $\mathrm{Pv} 1$ & $\begin{array}{c}\text { PJSC CB } \\
\text { "PrivatBank" }\end{array}$ & 0.508 & $\mathrm{Pv1}$ & "PrivatBank" & 0.453 \\
\hline
\end{tabular}

From the results of the research of competitive environment \#1, we note that with the greatest probability more than 50\% of clients will visit the PJSC CB "PrivatBank" Pv1 and more than $30 \%$ of the bank branch of PJSC AB "Stolichny". In this case, the role of the distance to be resolved to each of them has a decisive role in choosing between departments. However, in the case of PJSC "Imexbank", which is almost at one distance with the offices of PJSC CB "PrivatBank", its probability is much smaller, more than $12 \%$. This result can be explained by the lower level of attractiveness of the department itself for customers.

In another competitive environment \#2, the likelihood that customers will choose the branch of PJSC CB "PrivatBank" Pv1 decreased in comparison with the forex example and amounted to $45.3 \%$. At the same time, the other two banks of PJSC AB "Stolichny" and PJSC "National Credit" have similar values of probabilities, although they are at different distances from the client "1". Consequently, we can conclude that a significant influence on the frequency of the visit of one or another branch of the bank carries out the very complex indicator of the attractiveness of the branch, and not the distance that needs to be addressed by the client in order to distaff to him. Generalized results of probability calculations $\left(P_{i j}\right.$ (I) and $P_{i j}$ (II) - for a satisfactory set of competitors). The visit of potential clients of group \#1 (based on the analysis of a representative sample) of PJSC CB "Privat-Bank" (Pv1) shows Table 4.

Table 4. Summary results of the study

\begin{tabular}{|c|c|c|c|c|c|c|c|c|c|c|c|}
\hline Bank & $p_{i j}$ & $a_{1}$ & $a_{2}$ & $a_{3}$ & $a_{4}$ & $a_{5}$ & $a_{6}$ & $a_{7}$ & $d_{i j}^{\lambda}$ & $P_{i j}(\mathrm{I})$ & $P_{i j}(\mathrm{II})$ \\
\hline $\mathrm{I}$ & 3.9 & 7.5 & 5.2 & 5.9 & 7.6 & 3.9 & 7.1 & 5.8 & 830 & 0.127 & \\
\hline $\mathrm{S}$ & 1.6 & 6.4 & 7.4 & 7.7 & 7.0 & 4.9 & 5.6 & 6.6 & 940 & 0.308 & 0.275 \\
\hline $\mathrm{NC}$ & 1.4 & 7.7 & 5.3 & 5.9 & 7.8 & 4.4 & 7.2 & 5.6 & 775 & & 0.227 \\
\hline Pv2 & 1.4 & 5.7 & 7.0 & 7.6 & 6.3 & 4.5 & 4.4 & 6.2 & 1215 & 0.048 & \\
\hline Pv3 & 3.0 & 5.4 & 6.4 & 7.6 & 3.9 & 3.9 & 4.4 & 5.9 & 1100 & & \\
\hline H & 3.8 & 4.3 & 5.2 & 7.7 & 4.1 & 5.5 & 4.7 & 7.9 & 1030 & & 0.018 \\
\hline Sb & 4.5 & 5.4 & 5.2 & 8.2 & 4.1 & 5.3 & 4.1 & 8.2 & 1200 & & \\
\hline UP & 4.4 & 4.2 & 5.5 & 7.9 & 3.8 & 5.3 & 4.9 & 7.9 & 1070 & & \\
\hline UC & 1.5 & 5.2 & 6.6 & 6.1 & 5.8 & 4.5 & 7.2 & 7.9 & 1045 & & 0.027 \\
\hline A & 1.5 & 5.3 & 3.7 & 6.7 & 4.6 & 3.7 & 6.6 & 7.8 & 1005 & & \\
\hline N & 1.0 & 4.0 & 4.1 & 4.3 & 5.4 & 3.1 & 6.7 & 4.6 & 1215 & & \\
\hline O & 3.4 & 4.9 & 4.1 & 3.8 & 6.1 & 3.9 & 6.4 & 4.4 & 515 & 0.009 & \\
\hline Pv1 & 5.6 & 7.5 & 6.1 & 5.4 & 8.8 & 5.4 & 5.7 & 6.4 & 745 & 0.508 & 0.453 \\
\hline RS & 5.8 & 7.4 & 5.0 & 5.8 & 8.9 & 5.08 & 4.3 & 6.4 & 340 & & \\
\hline
\end{tabular}


Summarizing the results of the study, we draw the following conclusions:

$>$ for the construction of the model, based on the peculiarities of the organization of activity of the banking branches, a list of 7 criteria was determined that determine its attractiveness;

$>$ investigated the branch network of PJSC CB "PrivatBank" in Sumy, on the basis of which the city was divided into 10 zones according to the belonging of this or that district relative to the branches of this bank;

$>5$ were chosen for the research, where 10 groups of clients were allocated;

$>$ a layout of the questionnaire for collecting input data is proposed;

$>$ Field research was conducted among the representatives of the group of clients " 1 " and on its basis a sample was formed, the assessments of which served as inputs for further research;

$>$ in accordance with the found coefficients of the multiple correlation, determination, Fisher and Student criteria, and also the Goldfeld-Kwondt test, one can conclude that the constructed model is adequate and the obtained regressions are reliable;

$>$ the results of the conducted simulation showed that the significant influence on the probability of visiting the investigated departments of the banks carries out a comprehensive assessment of the attractiveness of the branch, and not the distance that the client overcomes with it.

\section{Conclusion}

When managing the effectiveness of the regional sales network and for improving the quality of customer service, it is important to study the competitive advantages of the bank. When adopting strategic decisions by customers, the basis for shaping the competitiveness profile of a bank is its financial efficiency, stability and stability, reputation, brand, etc., and when choosing a pointless service point, some other criteria are already being taken into account: the location of a branch / department, Service speed, schedule and quality of work, etc. In the second case, one of the tasks of controlling the efficiency of the stationary channels of sales of banking services is to assess the probability of visiting clients of the branch / department of the bank. This problem is solved in the paper by constructing a gravitational model, which is a modification of Huff's multiplicative interaction model and allows to calculate the probability of visiting clients of a specific branch / branch of the bank, as well as points of sale of competitors' banks in the chosen territorial zone and other channels of marketing of banking services of the investigated bank.

Practical calculations were made on the example of the study of branches of 14 banks located in the central part of Sumy. In order to calculate the elasticity criteria of each indicator of the bank's work, a system of regression equations is constructed, the adequacy of which is shown by the value of the multiplication coefficient coefficient at 0.92 and the determination coefficient at 0.84 , the predominance of the calculated values of the F-criterion and the t-criterion over Tabular. The analysis showed that the greatest influence on the level of attractiveness of the investigated department for customers is: the quality of the vehicle parking space, the quality of personnel and the timetable of the department, the coefficients of regression for which were respectively $3.91 ; 3.43$ and 3.16. The data obtained is the basis for the bank's decision on the appropriateness of opening a new branch in a certain settlement or territorial zone, to determine the expected number of bank clients, their maintenance costs in it, the share of the territorial market occupied by the investigated bank, as well as the evaluation of the efficiency of stationary sales of banking services.

\section{References}

1. Aigner, D., Schmidt, P. (1997). Formulation and estimation of stochastic frontier production function models. Journal of Econometrics, 6, 21-37.

2. Al-Najjar, S.M., Kalaf, K.H. (2012). Designing a balanced scorecard to measure a bank's performance: a case study. International Journal of Business Administration, 44-53.

3. Aleskerov, F., Ersel, H. \& Yolalan, R. (2004). Multicriterial ranking approach for evaluating bank branch performance. International Journal of Information Technology \& Decision Making. 3(2), 321-335.

4. Banker L.E., Charnes, A., Cooper, W., Maindiratta, A. (1988). A Comparison of DEA and Translog Estimates of Production Frontiers Using Simulated Observations from a Known Technology. Applications of Modern Production Theory: Efficiency and Productivity, 9, 33-55.

5. Berger, A.N., Dick, A.A., Goldberg, L.G., White, L.J. (2005). The Effects of Competition from Large, Multimarket Firms on the Performance of Small, Single-Market Firms: Evidence from the Banking In- 
dustry. Board of Governors of the Federal Reserve System Finance and Economics Discussion. Series 2005-15.

6. Catalon, R.T. (2004). Banking channel management: global trends and strategies. Massachusetts Institute of Technology. Retrieved from http://hdl.handle.net/1721.1/17860.

7. Fox, B. (2013). EU banks closed 5,500 branches in 2012. Economic Affairs. Retrieved from http://euobserver.com/economic/121084.

8. Heffernan, S. (1996). Modern Banking in Theory and Practice. Chichester: John Wiley \& Sons,.

9. Hirtle, B. (2007). The impact of network size on bank branch performance. Journal of Banking and Finance, 31, 3782-3805.

10. Hirtle, B., Stiroh, K. (2007). The return to retail and the performance of US banks. Journal of Banking and Finance, 31, 1101-1133.

11. Parasuraman, A., Zeithaml, V.A., Berry, L.L. (1988). SERVQUAL: A Multiple-Item Scale for Measuring Consumer Perceptions of Service Quality. Journal of Retailing, 64(1), 12-37.

12. Parkan, C. (1987). Measuring the efficiency of service operations: service operations: an application to bank branches. Engineering Costs and Production Economics, 12, 237-242.

13. Veenstra, A.D. (2012). Is there a future for bank branches? Marketing \& Strategy. Retrieved from http://blogs.forrester.com.

14. Wruuck, P. (2013). Bank branches in Europe - trends and driving forces [Electronic source]. Deutsche Bank Research. Retrieved from http://www.dbresearch.com.

\section{Appendix}

Table 1. Average values of the criteria for all branches of banks settled in the research area of Sumy

\begin{tabular}{|c|c|c|c|c|c|c|c|c|c|}
\hline \multirow[b]{2}{*}{ Title of the bank } & \multicolumn{9}{|c|}{ Evaluation criteria } \\
\hline & 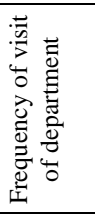 & 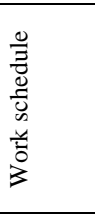 & 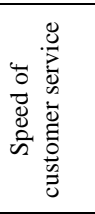 & 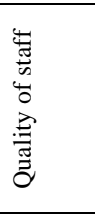 & 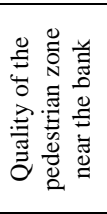 & 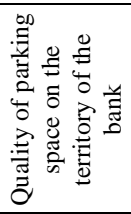 & 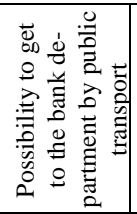 & 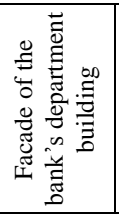 & 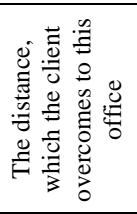 \\
\hline PJSC "Imexbank" & 3,867 & 7,500 & 5,233 & 5,900 & 7,567 & 3,967 & 7,133 & 5,767 & 830,000 \\
\hline PJSCAB “Stolichny” & 1,633 & 6,400 & 7,400 & 7,733 & 7,033 & 4,967 & 5,633 & 6,567 & 940,000 \\
\hline PJSC "National Credit" & 1,367 & 7,733 & 5,300 & 5,900 & 7,800 & 4,367 & 7,233 & 5,567 & 775,000 \\
\hline PJSC CB "PrivatBank" & 1,433 & 5,733 & 7,033 & 7,633 & 6,300 & 4,533 & 4,400 & 6,167 & 1215,000 \\
\hline PJSC KB “PrivatBank” PJSC KB & 3,033 & 5,400 & 6,400 & 7,567 & 3,967 & 3,933 & 4,433 & 5,967 & 1100,000 \\
\hline PJSC CB “Khreshchatyk” & 3,800 & 4,300 & 5,200 & 7,700 & 4,067 & 5,467 & 4,700 & 7,900 & 1030,000 \\
\hline PJSC "DB Sberbank of Russia” & 4,500 & 5,400 & 5,200 & 8,167 & 4,067 & 5,267 & 4,100 & 8,167 & 1200,000 \\
\hline PJSC "Ukrainian Professional Bank" & 4,433 & 4,200 & 5,467 & 7,867 & 3,767 & 5,333 & 4,900 & 7,900 & 1070,000 \\
\hline PJSC CB "UniCreditBank" & 1,500 & 5,200 & 6,633 & 6,067 & 5,767 & 4,467 & 7,233 & 7,867 & 1045,000 \\
\hline PJSC “Alfa-Bank" & 1,533 & 5,300 & 3,667 & 6,700 & 4,633 & 3,700 & 6,633 & 7,767 & 1005,000 \\
\hline PJSC KB "Nadra" & 1,000 & 4,000 & 4,100 & 4,333 & 5,433 & 3,067 & 6,733 & 4,633 & 1215,000 \\
\hline JSC “Oschadbank” & 3,367 & 4,933 & 4,100 & 3,833 & 6,067 & 3,933 & 6,433 & 4,367 & 515,000 \\
\hline PJSC CB "PrivatBank" & 5,633 & 7,467 & 6,067 & 5,433 & 8,833 & 5,433 & 5,733 & 6,433 & 745,000 \\
\hline PJSC "Bank Russian Standard" & 5,767 & 7,433 & 5,033 & 5,800 & 8,867 & 5,833 & 4,300 & 6,367 & 340,000 \\
\hline
\end{tabular}




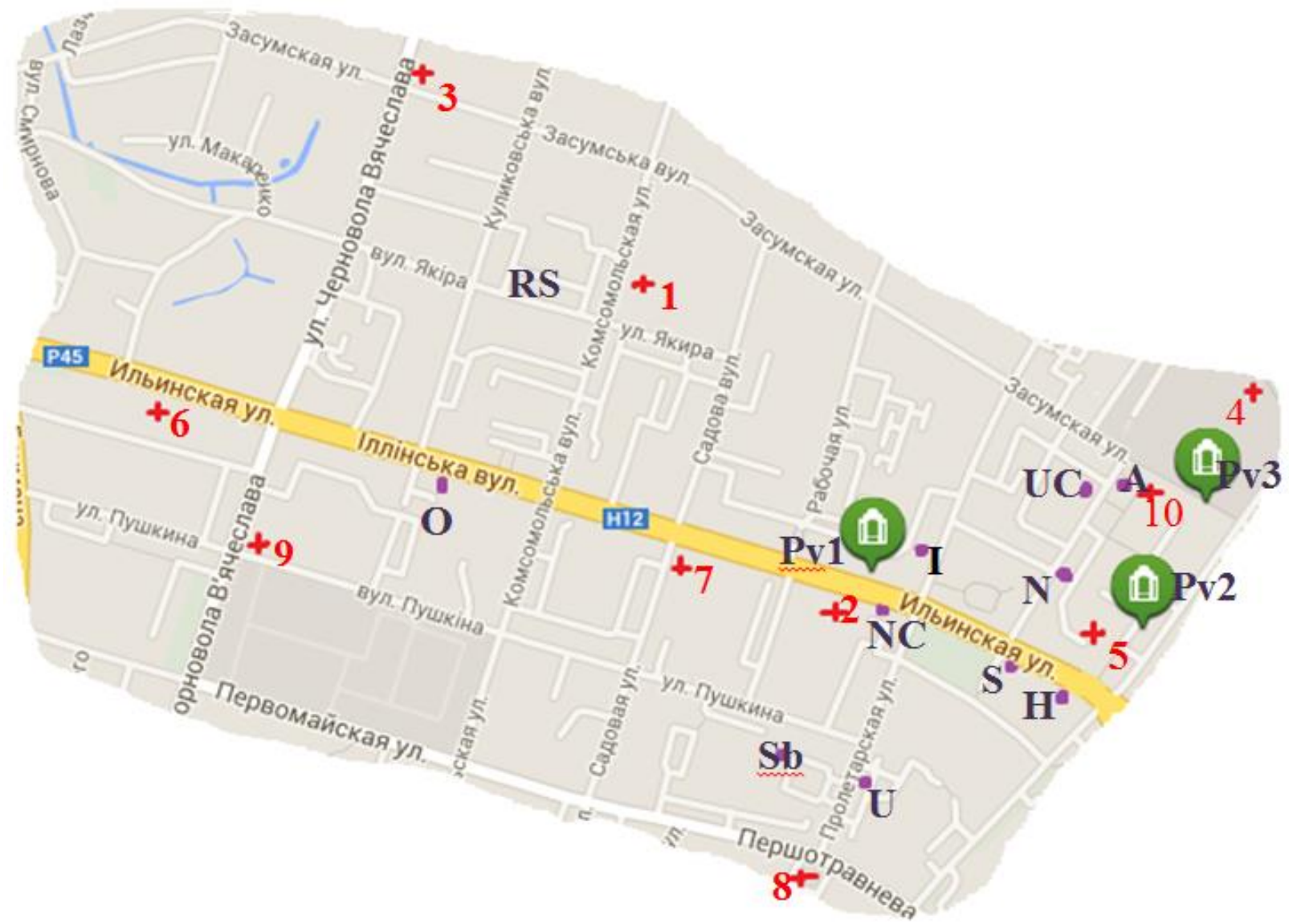

Figure 2. Map of the Sumy exploration area with branches of other banks and client groups deposited on it 